\title{
MERCURY TOXICITY- A PUBLIC HEALTH CONCERN
}

Deepak Jain, Mohd Inayatullah Khan, Parag B. Nehete, Patil Swapnil K, Priyanka Bhushan

1. Reader. Department of Conservative \& Endodontics, Krishna Institute of Dental Sciences. Karad.

2. Tutor. Department of Physiology, Rajiv Gandhi Institute of Medical Sciences, Adilabad, Andhra Pradesh.

3. Senior Lecturer. Department of Conservative \& Endodontics, SMBT Dental College, Sangamner Taluk.

4. Senior Lecturer. Department of Pedodontics \& Preventive Dentistry, SMBT Dental College, Sangamner Taluk.

5. Senior Lecturer. Department of Public Health Dentistry, SMBT Dental College, Sangamner Taluk.

\section{CORRESPONDING AUTHOR}

Mohd Inayatullah Khan.

Tutor, Department of Physiology,

Rajiv Gandhi Institute of Medical Sciences,

Adilabad, Andhra Pradesh

E-mail: drkhan123@rediffmail.com

Ph: 00919948959937

\begin{abstract}
Mercury is one of the most toxic elements of periodic table. It is a non-degradable environmental pollutant. Mercury has been used in dental amalgams since a long time. However concerns of mercury toxicity from this source have been debated. This article provides with an overview of the toxicology of the different forms of mercury to which human exposure occurs, and addresses methods to safely handle mercury waste generated in dental clinics.
\end{abstract}

KEY WORDS: Mercury, dental amalgam, toxicity

INTRODUCTION: Mercury has been used since time immemorial in medical, chemical and other electronic applications. Its use in dental amalgam is an area of concern because dental practitioners are at risk of continuous exposure to mercury vapor. Mercury use in dental amalgams is becoming a contentious issue due to its adverse effects associated with exposure to mercury and mercury compounds. It is imperative that the dental practitioner understands the hazards associated with the use of mercury, and controls exposures to prevent the development of any untoward effects and knows to handle the mercury waste that is generated in dental clinics [1].

FORMS OF MERCURY: Mercury exposure occurs in three basic forms; elemental, inorganic and Organic [2]. Elemental mercury exposure occurs from industrial waste, old thermometers, mercury sphygmomanometers, and other electronic equipments.

Inorganic mercury is in form of powder or crystals, it is ionic form of mercury which has been reacted with anions like sulfur or oxygen. Some batteries contain inorganic mercury. In past it was used in medicine as antiseptic, in creams and preservative, which eventually have been eliminated due to its potential hazards, but some Ayurvedic medicines still continues to use it [3].

Organic mercury is bond to organic compounds such as (methyl or ethyl) the methyl form is called as methyl mercury which accumulates in sea organisms like fish, shell fish etc. dental amalgams and mercury leakage from the amalgams is methylated by mouth bacteria. The ethyl mercury is from sodium ethylmercyrithosalicylate (thimerosal) used in vaccines and eye drops as preservative. However the use of thimerosal is greatly reduced due to its autism concerns [4]. 
DENTAL AMALGAM AND MERCURY: Silver amalgam, the material most commonly used for dental fillings, has a mercury content of about 50 per cent. Elemental or metallic mercury is the form used in dental amalgam. One of the areas of interest is in those patients with multiple different metal fillings. The problem with multiple metals is that they have different electrical potentials, thus they form an electrical current in which saliva acts as a conductor this results in increased dissolution of the mercury. Greater care should be taken during amalgam removal. A growing number of dentists are now practicing removing of amalgams with minimal mercury release [5].

MERCURY TOXICITY: one of the important areas of concern is mercury toxicity. Mercury exists in many chemical forms and differential toxic effects manifested by each from. The dental personnel using amalgam restoration is exposed to metallic [Elemental] form of mercury. The primary route of exposure to metallic mercury is inhalation this is because of its low vapor pressure. It is essentially odorless and has limited warning properties. Workers at risk of experiencing biological effects because of chronic exposure are often unaware that significant exposure is occurring [1]. Of particular public health concern has been possible neurologic impairment associated with prolonged exposure to elemental mercury [6,7]. Elemental mercury easily diffuses across the Blood-Brain Barrier especially in children. Ionized mercury deposits in various tissues in the body over a period of time. Elemental mercury vapor, such as may be present in the workplace, is readily absorbed through the lung tissue and is then taken up by several tissue types through passive diffusion. In particular are the kidney tissue and RBCs. As amount of mercury exposure levels go up, the kidneys are gradually damaged and their excretion of mercury becomes impaired.

In children urinary mercury levels were reported to be highly correlated with both number of amalgam fillings and time since placement [8]. Release of mercury vapour from amalgam restorations is known to occur but intensive research over the past three decades have failed to identify deleterious health outcomes $[9,10]$. This is likely to be due to insufficient mercury being released from dental amalgam restorations to cause a medical problem $[11,12]$. Although significantly higher mercury levels have been found in the blood and urine of dental personnel, their general health problems have not been found to differ significantly from persons not occupationally exposed to mercury [10].

MERCURY SAFETY: Amalgam waste can be generated from amalgam abrasion and from the placement and replacement of fillings. If amalgam waste is not managed properly, mercury can enter the environment. Although mercury vapor generated during amalgam filling preparation can be toxic, it is the organic mercury products, methyl and ethyl mercury, that have a higher toxic potential [13]. Organic mercury products can enter the environmental system due to biodegradation of amalgam waste [14]. It has been estimated that 3-70\% of mercury load of wastewater management facilities is related to dentistry [14]. Elemental mercury waste is managed by storing it in sealed resistant containers or react mercury with silver alloy to from scrap amalgam and submerge this amalgam particles in a fixer solution, because fixers are known to act as mercury vapor suppressant [15]. Do not place elemental mercury in garbage or wash down drains. Lost or extracted teeth amalgam fillings and amalgam contained waste such as trituration capsules and cotton rolls should be stored separately. All mercury contained materials should be labeled biohazard and managed accordingly. 
CONCLUSIONS: Mercury has been in use in dental amalgam since a long time. But with recent concerns of mercury toxicity and safety are critical issues of concern. When mercury is used in work places it is essential to follow a sound mercury handling practices. More awareness among the dental personnel and use of work practices that minimize exposure are critical elements. Lastly use of alternative dental materials in place of mercury whenever feasible is the solution.

\section{REFERENCES:}

1. Kostyniak, Paul J 'Mercury as a potential hazard for the dental practitioner' New York State Dental Journal 64. 4 (Apr 1998): 40-3. PMID:9613096

2. Echeverria D, Aposnian HV, Woods JS, Heyer NJ, Aposhian MM, Bittner AC, et al. 1998. Neurobehavioral effects from exposure to dental amalgam: new distinctions between recent exposure and $\mathrm{Hg}$ body burden. FASEB J 12:971-980.

3. Saper RB, et al; Lead, mercury, and arsenic in US- and Indian-manufactured Ayurvedic medicines sold via the Internet. JAMA. 2008 Aug 27;300(8):915-23. PMID:18728265.

4. Pizzorno, Joseph. Is Mercury Toxicity an Epidemic? (Part II) Integrative Medicine 10. 5 (Oct/Nov 2011): 54-57.

5. S. M. Koral, IAOMT Safe Removal of Amalgam Fillings, International Academy of Oral Medicine \& Toxicology, 2007.

6. Clarkson TW. 2003. Three modern faces of mercury. Environ Health Perspect 110:1123.

7. Echeverria D, Aposnian HV, Woods JS, Heyer NJ, Aposhian MM, Bittner AC, et al. 1998. Neurobehavioral effects from exposure to dental amalgam: new distinctions between recent exposure and Hg body burden. FASEB J 12:971-980.

8. Woods, James S; et al. Environmental Health Perspectives Environ Health Perspect. 2007 October; 115(10): 1527-1531.

9. ADA Council on Scientific Affairs. Dental amalgam: update on safety concerns. J Am Dent Assoc 1998; 129: 494 - 503.

10. Yip H K. Dental amalgam and human health. Int Dent J 2003; 53: 464-468.

11. Jones D W. Putting dental mercury pollution into perspective. Br Dent J 2004; 197: 175-177.

12. Osborne J W, Albino J E. Psychological and medical effects of mercury intake from dental amalgam. A status report for the American Journal of Dentistry. Am J Dent 1999; 12: 151-156.

13. 1a. Dodes JE. The amalgam controversy. An evidence-based analysis. J Am Dent Assoc 2001; 132(3):348-56.

14. Hiltz M. The environmental impact of dentistry. J Can Dent Assoc 2007; 73(1):59-62.

15. Mohd Inayatulla Khan et al; Bio-Waste Management In Dental Clinics jour of rural dental practice jrpd 2012; vol 1 (1),june -august 48-52. 